\title{
Assessment of Health-Related Quality of Life in Patients Receiving Regular Hemodialysis
}

\author{
Mahmoud A. Abdelghany ${ }^{1^{*}}$, Eman E. Elgohary ${ }^{2}$ and Yasser A. Nienaa ${ }^{3}$ \\ ${ }^{1}$ Nephrology specialist, Assistant Professor of Internal Medicine and Nephrology, Alexandria University, Egypt \\ ${ }^{2}$ Professor of Internal Medicine and Nephrology, Alexandria University, Egypt
}

${ }^{3}$ Nephrology Department, Faculty of medicine, Alexandria University, Egypt

\begin{abstract}
This cross-sectional descriptive study was carried out at the hemodialysis unit of Karmouz Health Insurance Hospital, Alexandria, Egypt. The study was conducted on adult End-stage renal disease (ESRD) patients maintained on regular hemodialysis treatment for $\geq 1$ year. Aim was to assess self-perception of ESRD patients undergoing regular Hemodialysis (HD) of their health-related quality of life (HRQOL) and explore resulted scores using kidney disease quality of life short form 36 instrument (KDQOL SF-36). A total of 81 eligible patients joined the study (49 males and 32 females). Aged $50.6 \pm 12.7$ years. Results showed that HRQOL of HD patients was very poor in all domains. The mean total score was below 50 (out of 100 point) with mean Physical Health Composite (PHC) $=35.57$ \pm 7.34 and mean Mental Health Composite $(\mathrm{MHC})=36.76 \pm 10.22$. In general, scores were relatively higher in males, younger age groups, high educational level, employed and/or higher family income. Regarding clinical prolife, this study showed that scores were lower among patients suffering anemia, dyslipidemia, hypoalbuminemia and/or those with comorbidities. Scores for general health survey were significantly lower in anemic patients (with hemoglobin level $<11 \mathrm{~g} / \mathrm{dL}$ ). Working patients had significantly higher scores than non-working or retired. The study also showed that employment was the only significant predictor for total HRQOL score in a multiple linear regression model was designed to predict total score, while controlling for hemoglobin level, age, duration of being on HD $(p=0.028)$.
\end{abstract}

Keywords: End stage renal disease; Health related quality of life; Hemodialysis; Kidney disease quality of life short form; Anemia; Employment

\section{Introduction}

End-stage renal disease is a non-curable condition imposes a considerable burden on patients and their families [1,2]. It's been proven that the patient's perception is more important than the clinical assessment in determining HRQOL. Culture and values plays a vital role in shaping perception of HRQOL [3]. Although advances in HD treatment have contributed to improved patients' survival, they're still subjected to multiple threats and stressors that may worsen their HRQOL [4]. Lower HRQOL scores were strongly associated with higher morbidity and mortality [3]. The aim of the present study was to assess self-perception of patients with ESRD undergoing regular hemodialysis of HR-QOL, to study their epidemiological features, assess HR-QOL scores and explore its clinical correlates.

\section{Patients and Methods}

This cross-sectional descriptive study was carried out in September 2015 at the hemodialysis unit of Karmouz Health Insurance Hospital, Alexandria, Egypt. Among all adult ESRD patients aged $>18$ years and maintained on regular hemodialysis treatment for $\geq 1$ year, 81 eligible patients joined the study. (As exclusion criteria were: dementia, psychotic disorder, malignancy, active infection(s), acute medical or surgical condition, hospitalization within the prior month and physical or mental handicaps). A validated Arabic form of kidney disease quality of life short form (KD QOL SF-36) version 1.3 questionnaire was used as a self-report instrument to measure HR-QOL. Patients were encouraged to complete the questionnaire at the field of study and not at home, however some patients insisted to take it home and bring it back the next session. Most patients completed the questionnaire on their own, some patients -for various reasons e.g. being illiteratecompleted the survey with assistance of the researcher or a coworker. The KDQOL Instrument is a self-report measure developed for individuals with kidney disease and on dialysis. It captures their perceptions about concerns of symptoms or problems, effects and burden of kidney disease, work status, sleep, cognitive, social and sexual function. It also measures additional quality of life scales include: social support, dialysis staff encouragement and patient satisfaction [5]. The item related to sexual activity was considered it as an optional item to respect patients' privacy. It was missing in half of the patients yet we took that into consideration while doing analysis of the data.

All collected data checked for validity. Scoring was done to obtain universal scores ranging from 0 to 100 , as higher scores indicate better QOL. Data entry and statistical analysis were performed using SPSS 18.0 statistical software package (SPSS Inc., Chicago, IL, USA). The distributions of quantitative variables were tested for normality using Kolmogorov-Smirnov test, which revealed that the data were normally distributed. Correlation between quantitative variables done using Pearson correlation test. Comparing quantitative variables between 2 groups of cases was conducted using independent t-test. Comparing quantitative variables between 3 groups or more of cases was conducted using oneway ANOVA. Kruskal Wallis test was used when sample size per group was small. Statistical significance was set at $\mathrm{P}<0.05$.

\section{Results}

Among the $81 \mathrm{HD}$ patients studied (49 males +32 females) aged $50.6 \pm 12.7$ years, HRQOL scores were poor in all domains and subscales. The mean total score was $47.2 \pm 25.2$, mean Physical Health Composite $(\mathrm{PHC})=35.57 \pm 7.34$ and mean Mental Health Composite

*Corresponding author: Mahmoud A. Abdelghany, Nephrology Specialist, Assistant Professor of Internal Medicine and Nephrology, Alexandria University, Egypt, Tel: 20100680 795; E-mail: amamh2@hotmail.com

Received: March 18, 2016; Accepted: April 02, 2016; Published: April 09, 2016

Citation: Abdelghany MA, Elgohary EE, Nienaa YA (2016) Assessment of HealthRelated Quality of Life in Patients Receiving Regular Hemodialysis. J Nephrol Ther 6: 246. doi:10.4172/2161-0959.1000246

Copyright: (C) 2016 Abdelghany MA, et al. This is an open-access article distributed under the terms of the Creative Commons Attribution License, which permits unrestricted use, distribution, and reproduction in any medium, provided the original author and source are credited. 
$(\mathrm{MHC})=36.76 \pm 10.22$. Regarding the ESRD- targeted areas, the mean total score was $54.48 \pm 25.65$, the highest score was for dialysis staff encouragement scale $(73.15 \pm 23.64)$ followed by social support scale $(72.22 \pm 25.14)$ and quality of social interaction (71.52 \pm 18.74$)$. However, burden of kidney disease and work status scales yielded the lowest scores $(25.62 \pm 26.62$ and $30.86 \pm 37.56$ respectively). Sleep scale score was $50.22 \pm 21.27$. Only 40 patients responded to sexual activity inquiries and scored $66.88 \pm 32.71$ on sexual function scale (Table 1). On the 36-item health survey, the mean total score was 36.5 \pm 25.67 . Emotional well-being and physical functioning scales yielded the highest score but were below $50(48.3 \pm 23.04$ and $46.91 \pm 27.79$ respectively). The lowest scores represented the role limitations caused by physical and emotional health problems $(21.6 \pm 31.56$ and $24.69 \pm$ 35.27). Pain scale score was $40.31 \pm 23.18$. Finally, the score overall heath rating scale was $53.09 \pm 16.63$. On comparing scores in both sexes (Table 1), females' scores were lower than males in mean total score ( $44.9 \pm 23.7$ and $49 \pm 25.7$ respectively) and all scales, except for the sexual function, social support scales and overall health rating item where female scores were relatively higher (Figures 1 and 2).

Unemployed and/or anemic patients had statistically significant reduced HRQOL $(\mathrm{P}=0.03, \mathrm{P}=0.02$ respectively) (Table 2$)$. Scores varied according to age, sex, marital status, education level, presence of co-morbidities, dyslipidemia and hypoalbuminemia but without statistical significance. Multiple linear regression analysis for scores demonstrated that working status was the only significant predictor (employed patients' scores were higher than unemployed ones by 8.648 units, while controlling other predictors $(\mathrm{p}=0.028)$ (Table 3 ).

\section{Discussion}

Long-term HD treatment often results in financial troubles, loss of

\begin{tabular}{|c|c|c|c|}
\hline Domains and subscales & Mean & Median & SD \\
\hline \multicolumn{4}{|c|}{ ESRD- targeted areas } \\
\hline Symptom/problem list & 49.97 & 52.08 & 23.08 \\
\hline Effects of kidney disease & 51.04 & 50 & 24.49 \\
\hline Burden of kidney disease & 25.62 & 18.75 & 26.62 \\
\hline Work status & 30.86 & 0 & 37.56 \\
\hline Cognitive function & 62.96 & 60 & 21.55 \\
\hline Quality of social interaction & 71.52 & 73.33 & 18.74 \\
\hline Sexual function & 66.88 & 75 & 32.71 \\
\hline Sleep & 50.22 & 47.50 & 21.27 \\
\hline Social support & 72.22 & 83.33 & 25.41 \\
\hline Dialysis staff encouragement & 73.15 & 75 & 23.64 \\
\hline Patient satisfaction & 44.86 & 50 & 27.09 \\
\hline \multicolumn{4}{|c|}{ The 36-item Health Survey } \\
\hline Physical functioning & 46.91 & 45 & 27.79 \\
\hline Role limitations--physical & 21.60 & 0 & 31.56 \\
\hline Pain & 40.31 & 35 & 23.18 \\
\hline General health & 34.14 & 30 & 21.09 \\
\hline Emotional well-being & 48.30 & 48 & 23.04 \\
\hline Role limitations--emotional & 24.69 & 0 & 35.27 \\
\hline Social function & 42.59 & 50 & 24.27 \\
\hline Energy/fatigue & 33.46 & 30 & 19.18 \\
\hline Overall health & 53.09 & 50 & 16.63 \\
\hline Total score & 47.22 & 43.65 & 25.21 \\
\hline $\begin{array}{c}\text { SF-12 Physical Health } \\
\text { Composite }\end{array}$ & 35.57 & 35.33 & 7.34 \\
\hline $\begin{array}{l}\text { SF-12 Mental Health } \\
\text { Composite }\end{array}$ & 36.76 & 35.97 & 10.22 \\
\hline
\end{tabular}

Table 1: KDQOL SF-36 scores for all studied patients.

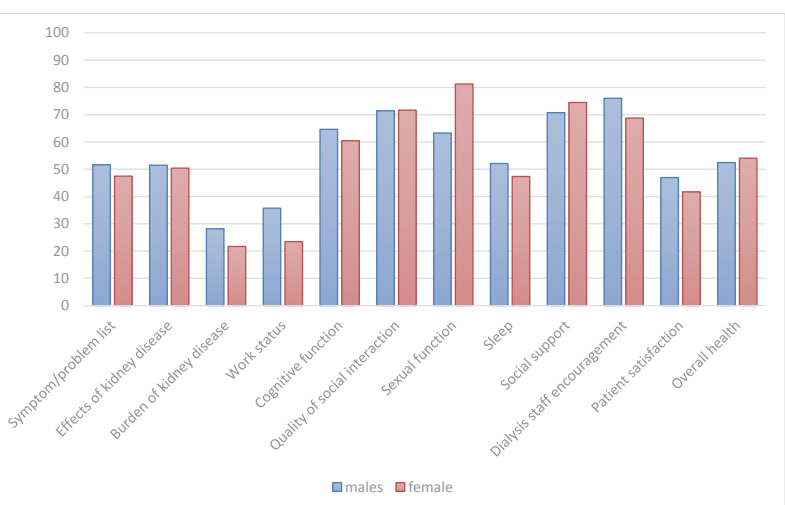

Figure 1: HRQOL scores for ESRD- targeted areas.

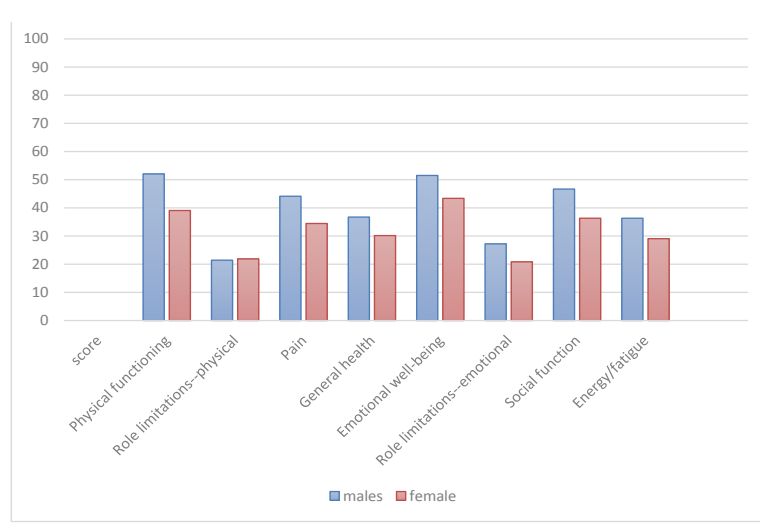

Figure 2: The general health survey scores.

freedom, dependence on health care personnel and caregivers, negative impacts on marital status, family, and social activities. Thus, quality of life should be measured and monitored for better understanding of patients' condition [6]. This can also help to identify subgroups with relatively poor perceived health and guide interventions to improve their situations and avoid further serious consequences [4]. Over the years, consensus has been established that HRQOL is a multidimensional concept. As such, assessment of HRQOL generally covers physical, social, and psychological domains [4]. Several studies proved that HD patients suffer poor HRQOL, despite continuing advancements in the treatment [3,4,7-14]. Their HRQL is still much lower than general population $[12,15]$. Baseline measures of HRQOL were reduced in CKD patients in proportion to the severity grade of CKD [16]. Caregivers for ESRD patients may be affected as well, having a family member on maintenance dialysis therapy creates family burdens greater than those experienced by having a family member with several other chronic conditions [17]. Sexual function item left optional in our study for social issues and expressed by half of the patients. Its score was relatively high $(66.8 \pm 23)$. The Dialysis Outcomes and Practice Patterns Study (DOPPS) study in 2004 noticed variation in sexual function scores worldwide with mean scores 66.7, 63.3 and 60.5 for Europe, Japan and USA respectively with statically significant difference between Europe and USA [15]. In the present study, the mean of HRQOL scores were relatively higher in younger age groups in all domains, yet there was no statistically significant difference. The association of age with HRQOL is quite complex and illustrates the complexity of the QOL concept [4]. Some studies conducted in different countries also demonstrated 
Citation: Abdelghany MA, Elgohary EE, Nienaa YA (2016) Assessment of Health-Related Quality of Life in Patients Receiving Regular Hemodialysis. J Nephrol Ther 6: 246. doi:10.4172/2161-0959.1000246

Page 3 of 4

\begin{tabular}{|c|c|c|c|c|c|}
\hline \multirow[t]{2}{*}{ Work status* } & \multirow[t]{2}{*}{ Statistics } & \multicolumn{4}{|c|}{ HR QOL Scores } \\
\hline & & ESRD- targeted areas & General health survey & Overall health item & Total score \\
\hline \multirow[t]{5}{*}{ Working $(n=23)$} & $\overline{x \pm S . D .}$ & $61.77 \pm 17.65$ & $41.42 \pm 17.63$ & $57.83 \pm 15.06$ & $53.31 \pm 16.13$ \\
\hline & Median & 65.91 & 33.31 & 50 & 52.93 \\
\hline & Min-Max & $15.57-97.73$ & $24.19-97$ & $40-100$ & $22.21-97.55$ \\
\hline & Std. Error & 3.68 & 3.68 & 3.14 & 3.36 \\
\hline & $95 \% \mathrm{Cl}$ & {$[54.1,69.4]$} & {$[33.79,49.0]$} & {$[51.3,64.3]$} & {$[46.3,60.29]$} \\
\hline \multirow[t]{5}{*}{ Not retired and not working $(n=34)$} & $x \overline{ \pm S} . D$ & $51.46 \pm 14.89$ & $34.74 \pm 17.75$ & $55.59 \pm 17.27$ & $44.78 \pm 14.92$ \\
\hline & Median & 52.19 & 32.36 & 60 & 43.91 \\
\hline & Min-Max & $21.35-90.91$ & $2.38-83.54$ & $10-100$ & $13.82-88.42$ \\
\hline & Std. Error & 2.55 & 3.04 & 2.96 & 2.56 \\
\hline & $95 \% \mathrm{Cl}$ & {$[46.3,56.66]$} & {$[28.55,40.9]$} & {$[49.6,61.6]$} & {$[39.6,49.99]$} \\
\hline \multirow[t]{5}{*}{ Retired and not working $(n=24)$} & $x \overline{ \pm S} . D$ & $49.13 \pm 11.48$ & $34.28 \pm 15.22$ & $45 \pm 14.74$ & $42.72 \pm 11.44$ \\
\hline & Median & 50.09 & 33.56 & 50 & 42.97 \\
\hline & Min-Max & $18.62-68.94$ & $1.13-72.58$ & $10-60$ & $14.56-65.76$ \\
\hline & Std. Error & 2.34 & 3.11 & 3.01 & 2.34 \\
\hline & $95 \% \mathrm{Cl}$ & {$[44.3,53.98]$} & {$[27.85,40.7]$} & {$[38.8,51.2]$} & {$[37.9,47.55]$} \\
\hline \multicolumn{6}{|c|}{ Test Statistics** } \\
\hline \multicolumn{2}{|l|}{$f$} & 4.91 & 1.35 & 4.52 & 3.66 \\
\hline \multicolumn{2}{|l|}{ df } & 2 & 2 & 2 & 2 \\
\hline \multicolumn{2}{|l|}{$P$ value } & 0.01 & 0.266 & 0.014 & 0.03 \\
\hline
\end{tabular}

*Working group included full or part time workers, not working and not retired group included housewives, patients who were searching for a job or who can't work due to their medical condition.

${ }^{* *}$ Oneway ANOVA

- 95\% Confidence Interval for mean [upper bound, lower bound]

Table 2: Comparing HR QOL scores between patients according to their work status using oneway ANOVA.

\begin{tabular}{|l|l|l|l|l|l|}
\hline Model & \multicolumn{2}{|l|}{$\begin{array}{l}\text { Unstandardized } \\
\text { Coefficients }\end{array}$} & $\begin{array}{l}\text { Standardized } \\
\text { Coefficients }\end{array}$ & t & Sig. \\
\hline & B & Std. Error & Beta & & \\
\hline (Constant) & 24.137 & 10.399 & & 2.321 & 0.023 \\
\hline $\mathrm{Hb}^{\mathrm{a}}$ & 8.841 & 4.658 & 0.206 & 1.898 & 0.062 \\
\hline Age & 0.214 & 0.159 & 0.184 & 1.342 & 0.184 \\
\hline HD duration & 0.215 & 0.48 & 0.051 & 0.448 & 0.655 \\
\hline Retired ${ }^{\mathrm{b}}$ & -6.030 & 4.402 & -0.187 & -1.370 & 0.175 \\
\hline Working $^{\mathrm{b}}$ & 8.648 & 3.858 & 0.265 & 2.242 & 0.028 \\
\hline
\end{tabular}

Dependent: Mean total score

$\mathrm{R}^{2}=0.15$, Model $\mathrm{F}=2.54, \mathrm{p}=0.035$

a: reference category is Anemic

$\mathrm{b}$ : reference category is Not working

Table 3: Multiple linear regression model to for HR QOL total score of hemodialysis patients.

that age was strongly inversely associated with the physical domain scores. As age increases in the elderly, physical function of the body decreases [2,4,14,18-22]. A recent Saudi showed that age was a negative predictor of HRQOL score [2]. Concerning gender, many studies of QOL in patients with ESRD have shown that women have lower scores on different QOL tests than men. This was observed in both pre-dialysis and dialysis patients. The reasons for poor QOL in women are not clear and seem to be related to psychological and social factors, rather than the illness itself $[12,23,24]$. This was consistent with the present study. It is of interest that Bayoumi et al 2014 showed reduced QOL scores in male patients and male sex was a negative predictor of QOL score [2]. Various factors such as geographic areas, ethnicity, sample size may explain this gender differences of QOL in HD patients [25]. Regarding work status, the current study revealed that HD patients' perception for work function and role of physical limitation scores were relatively

low ( $30.86 \pm 37.6$ and $21.6 \pm 31.6$ respectively). Only $28 \%$ of patients were employed (working full time or part time), the remaining were not working either due to being retired, in working-age and searching for a suitable job or can't work due to physical limitation. Whatever the cause the HRQOL scores were higher among the working group of patients in mean total score and ESRD targeted areas. Retired group ranked the least score. This difference was statistically significantly. And on applying a multiple Linear regression model to predict total scores, working group's scores were higher than non-working group by 8.648 units of total score while controlling for anemia state, (anemic/non-anemic), patient age, duration of being on hemodialysis treatment $(\mathrm{p}=0.028)$. The potential to increase the number of dialysis patients who are employed exists if the barriers to employment that have been identified can be removed [26]. Patients who are satisfied with hemodialysis treatment and accepting it have better working capacity [22]. Directing rehabilitation efforts toward the population of dialysis patients who identify themselves as willing and able to work seems a worthwhile strategy to improve their QOL [26]. Many sociodemographic and clinical factors can influence HRQOL of HD patients. Current study findings proved that future studies with more comprehensive and informative tools to focus on these variables and help us improve our knowledge about HRQOL determinants and in turn this will reflect on clinical practice to enhance their poor QOL status.

\section{Conclusion}

All domains of HRQOL were reduced in HD patients. Anemia and unemployment adversely affected HRQOL scores.

\section{References}

1. Soliman AR, Fathy A, Roshd D (2012) The growing burden of end-stage renal disease in Egypt. Ren Fail 34: 425-428. 
Citation: Abdelghany MA, Elgohary EE, Nienaa YA (2016) Assessment of Health-Related Quality of Life in Patients Receiving Regular Hemodialysis. J Nephrol Ther 6: 246. doi:10.4172/2161-0959.1000246

2. Bayoumi M, Al Harbi A, Al Suwaida A, Al Ghonaim M, Al Wakeel J, et al. (2013) Predictors of quality of life in hemodialysis patients. Saudi J Kidney Dis Transp 24: $254-259$

3. Joshi VD (2014) Quality of life in end stage renal disease patients. World $J$ Nephrol 3: 308-316.

4. Mollaoglu M (2013) Quality of Life in Patients Undergoing Hemodialysis. In: Suzuki $H$ (eds.) Hemodialysis, p: 823-843.

5. Hays RD, Kallich JD, Mapes DL, Coons SJ, Amin N, et al. (1997) Kidney Disease Quality of Life Short Form (KDQOL-SF), version1.3: A manual for use and scoring. RAND, Washington D.C.

6. Thaweethamcharoen $T$, Srimongkol $W$, Noparatayaporn $P$, Jariyayothin $P$ Sukthinthai N, et al. (2013) Validity and Reliability of KDQOL-36 in Thai Kidney Disease Patient. Value in Health 2: 98-102.

7. Abraham S, Venu A, Ramachandran A, Chandran PM, Raman S (2012) Assessment of quality of life in patients on hemodialysis and the impact of counseling. Saudi J Kidney Dis Transpl 23: 953-957.

8. Sathvik BS, Parthasarathi G, Narahari MG, Gurudev KC (2008) An assessment of the quality of life in hemodialysis patients using the WHOQOL-BREF questionnaire. Indian J Nephrol 18: 141-149.

9. Abdel-Kader K, Unruh ML, Weisbord SD (2009) Symptom burden, depression, and quality of life in chronic and end-stage kidney disease. Clin J Am Soc Nephrol 4: 1057-1064.

10. Jaar BG, Chang A, Plantinga $L$ (2013) Can we improve quality of life of patients on dialysis? Clin J Am Soc Nephrol 8: 1-4.

11. Sesso R, Rodrigues-Neto JF, Ferraz MB (2003) Impact of socioeconomic status on the quality of life of ESRD patients. Am J Kidney Dis 41: 186-195.

12. Valderrábano F, Jofre R, López-Gómez JM (2001) Quality of life in end-stage renal disease patients. Am J Kidney Dis 38: 443-464.

13. Rambod M, Shabani M, Shokrpour N, Rafii F, Mohammadalliha J (2011) Quality of life of hemodialysis and renal transplantation patients. Health Care Manag (Frederick) 30: 23-28

14. Stojanovic M, Stefanovic V (2007) Assessment of health-related quality of life in patients treated with hemodialysis in Serbia: Influence of comorbidity, age, and income. Artif Organs 31: 53-60.
15. Mapes DL, Bragg-Gresham JL, Bommer J, Fukuhara S, McKevitt P, et al. (2004) Health-related quality of life in the Dialysis Outcomes and Practice Patterns Study (DOPPS). Am J Kidney Dis 44: 54-60.

16. Mujais SK, Story K, Brouillette J, Takano T, Soroka S, et al. (2009) Healthrelated quality of life in CKD Patients: correlates and evolution over time. Clin J Am Soc Nephrol 4: 1293-1301.

17. Belasco AG, Sesso R (2002) Burden and quality of life of caregivers for hemodialysis patients. Am J Kidney Dis 39: 805-812

18. Blake C, Codd MB, Cassidy A, O'Meara YM (2000) Physical function employment and quality of life in end-stage renal disease. J Nephrol 13: 142 149

19. Simmons RG, Abress L (1990) Quality-of-life issues for end-stage renal disease patients. Am J Kidney Dis 15: 201-208.

20. Braga SF, Peixoto SV, Gomes IC, Acúrcio Fde A, Andrade El, et al. (2011) Factors associated with health-related quality of life in elderly patients on hemodialysis. Rev Saude Publica 45: 1127-1136.

21. Moura A, Madureira J, Alija P, Fernandes JC, Oliveira JG, et al. (2015) Effect of Aging in the Perception of Health-Related Quality of Life in End-Stage Renal Disease Patients under Online-Hemodiafiltration. Aging Dis 6: 17-26.

22. Anees M, Malik MR, Abbasi T, Nasir Z, Hussain Y, et al. (2014) Demographic factors affecting quality of life of hemodialysis patients - Lahore, Pakistan. Pak J Med Sci 30: 1123-1127.

23. Mingardi G, Cornalba L, Cortinovis E, Ruggiata R, Mosconi P, et al. (1999) Health-related quality of life in dialysis patients. A report from an Italian study using the SF-36 Health Survey. DIA-QOL Group. Nephrol Dial Transplant 14 1503-1510.

24. Moreno F, Gomez JML, Jofre R, Valderrabano F, Gonzalez L, et al. (1996) Quality of life in dialysis patients. A Spanish multicentre study Nephrol Dial Transplant 11: 125-129.

25. Einollahi B, Motalebi M (2014) Remarks about the study of predictors of quality of life in hemodialysis patients. Saudi J Kidney Dis Transpl 25: 881-882.

26. Curtin RB, Oberley ET, Sacksteder P, Friedman A (1996) Differences between employed and nonemployed dialysis patients. Am J Kidney Dis 27: 533-540. 